\title{
Case Study on the Mechanism of Influence of Stoppage on Ground Pressure under Different Rates of Advance
}

\author{
Xiaoxu Gao, ${ }^{1,2}$ Xinyu Shi $\mathbb{D}^{1,3}$ and Weibin Guo ${ }^{1,2}$ \\ ${ }^{1}$ Xi'an University of Science and Technology, Xi'an 710054, China \\ ${ }^{2}$ Key Laboratory of the Ministry of Education on Mining and Disaster Prevention in Western China, Xi'an 710054, China \\ ${ }^{3}$ Shaanxi Coal Group Huangling Mining Co., Ltd., Yan'an 727307, China
}

Correspondence should be addressed to Xinyu Shi; 390359325@qq.com

Received 28 February 2021; Accepted 13 July 2021; Published 22 July 2021

Academic Editor: Dezhong Kong

Copyright ( $\odot 2021$ Xiaoxu Gao et al. This is an open access article distributed under the Creative Commons Attribution License, which permits unrestricted use, distribution, and reproduction in any medium, provided the original work is properly cited.

\begin{abstract}
Because of daily maintenance, equipment damage, gas overrun, and other force majeure factors, the continuous stopping of the working face causes the roof pressure to accumulate, which leads to causing accidents such as coal wall spalling and roof falling. To address the roof safety problem caused by continuous stoppages, the 620 working face in the Huangling mining area is taken as the research object. Through field measurement, theoretical analysis, numerical simulation, and other research methods, the influence and mechanism of stopping pressure under different rates of advance are studied. The results show that the velocity factor of roof load transfer is positively correlated with the advancing velocity of the working face; the reasonable length of the suspended roof is mainly affected by the number of caving holes and the effect of pressure relief; and comparing the two stages of advance speed of $4.8 \mathrm{~m} / \mathrm{d}$ and $12.8 \mathrm{~m} / \mathrm{d}$, the periodic weighting step distance of the latter increases by $24.4 \%$ compared with the former, and the rate of increase of support load caused by stopping mining increases by $42.1 \%$ compared with the former. The roof pressure accumulation caused by stopping mining is increased. Taking appropriate measures for local forced caving of the working face can release the roof pressure and reduce the risk of local caving of the working face. The study can provide a theoretical basis for roof control of continuous stopping under similar engineering conditions.
\end{abstract}

\section{Introduction}

Due to force majeure factors such as daily maintenance of working face, equipment damage, special geological structures, and gas overrun, the continuous stoppage of mining in the normal advancing process of working face is inevitable, and the characteristics of ground pressure show obvious differences under different rates of advance [1]. In this regard, Xie [2-4] analysed the failure field and stress field of the fully mechanised top coal caving face under different rates of advance through numerical simulation and similar simulation methods. The results show that when the unit mining depth increases, the extent of failure zones in the rock around the working face decreases, but a large amount of energy accumulates inside the rock mass, and the possibility of local rock burst increases; according to Yang and Liu $[5,6]$, the integrity of surrounding rock and the volume of broken rock block are positively correlated with the rate of advance of working face in shallow coal seams; S. Yang and J. Yang [7-13] believed that, in high-intensity mining, the rate of occurrence of coal and rock disasters is affected by the rate of advance and the working face length. The greater the coal rock disaster rate, the greater the first weighting step of the working face roof; Zhu and $\mathrm{Xu}[14,15]$ analysed the damage to a coal and rock mass under different geological conditions by combining numerical simulation and field measurement methods. The analysis results show that the faster the working face advances, the greater the stress concentration on both sides of the working face, and the extent of the plastic zone is reduced. These research results used weighting characteristics of working face and coal and rock catastrophes under different rates of advance but fail to reveal the ground pressure on the working face when the mining is stopped. Due to special reasons, if the advance 
distance has not reached the collapse step distance, a large amount of energy accumulated in the roof cannot be released, the risk of a roof fall in the working face is greatly increased, and, at the same time, the hydraulic support movable column shrinks and the hydraulic pipe bursts. In view of this kind of engineering problem, the author, by means of numerical simulation and field measurement, took the 620 working face of a mine in the Huangling mining area as the research background and investigated the ground pressure behaviour upon continuous stoppage at the working face in the process of high-speed advance thereof.

At present, the 620 working face of No. 2 Coal Seam in Huangling coal mine is being mined. The average thickness of the coal seam is $2.4 \mathrm{~m}$, the dip angle is $0^{\circ}$ to $6^{\circ}$, the average burial depth of the working face is $380 \mathrm{~m}$, the width is $235 \mathrm{~m}$, the advancing length is $2267 \mathrm{~m}$, the current daily rate of advance is $12.8 \mathrm{~m} / \mathrm{d}$, the working face relies on the ZY6800/ $11.5 / 24 \mathrm{~d}$ hydraulic support to automatically support the roof, the rated support resistance is $6800 \mathrm{kN}$, and the support is equipped with a PM32 electrohydraulic control system, which can record the live column load in real time. The roof and floor of the coal seam are thus as follows: the main roof is siltstone and fine sandstone and the thickness is $11.8 \mathrm{~m}$; the direct roof is fine sandstone and the thickness is $8.7 \mathrm{~m}$; and the direct bottom is mudstone and the thickness is $2.8 \mathrm{~m}$. Due to force majeure factors such as daily maintenance, equipment damage, and gas overrun, the phenomenon of continuous stoppage affects mine safety. For face 620 , the phenomenon of support pressing and hydraulic pipe bursting occurs regularly during the stoppage of the 620 working face (Figure 1). The table of rock mechanics parameters is shown in Table 1.

\section{The Influence of Working Face Ground Pressure under Different Rates of Advance}

To analyse the influences of ground pressure and the performance characteristics of stoppage pressure under different rates of advance, two different advancing sections of the 620 working face are selected for in situ testing (Table 2 and Figure 2). The stoppage points marked in Figure 2 are caused by local gas overrun of the working face. According to an investigation of the mining area, when the rate of advance is $4.8 \mathrm{~m} / \mathrm{d}$ and $12.8 \mathrm{~m} / \mathrm{d}$, the basis for the judgment of periodic weighting is as follows: the end resistance of circulation reaches $35 \mathrm{MPa}$ and $25 \mathrm{MPa}$, respectively, the high-level gas drainage concentration increases instantaneously, and the coal wall spalling is severe. When the working face stops mining, the bearing degree of the support increases, but it has not reached the average load for periodic weighting. After stopping mining, the roof pressure will be released with the continuous advance of the working face.

Combined with the load conditions of support in Figures 2(a) and 2(b), the measured weighting characteristics are listed in Table 3. The measured results show that when the rate of advance is $4.8 \mathrm{~m} / \mathrm{d}$ and $12.8 \mathrm{~m} / \mathrm{d}$, the periodic weighting step distance of the latter is $24.4 \%$ higher than that of the former, and the support load rise rate caused by stoppage of the latter is $42.1 \%$ higher than that of the former, and the risk of roof fall of working face is greatly increased. Therefore, avoiding the fluctuation of the mining speed of the working face can decelerate the accumulation of dangerous roof pressure on the working face and play a positive role in the control of the rock strata; by comparing the rise of the support load when stopping mining under the two rates of advance, it is found that when the rate of advance is large, the accumulated pressure on the roof is also high, and the risk of a local roof fall in the working face is relatively low. Appropriate measures should be taken to release the roof pressure to ensure safe production at the working face.

\section{Theoretical Analysis}

3.1. Speed Factor of Load Transfer. Some research results show that, with the increase of the rate of advance, the peak load increases and moves forward [16-18]; and when the rate of advance is rapid, the mining failure caused by the direct roof is incomplete, the roof load increase caused by mining cannot fully act on the support, and the support load remains low $[19,20]$. On the other hand, when the main roof collapses, the main load is provided by the load layer on the top of the main roof. The load transfer process and the rate of advance have a time effect. That is, when the working face is advancing normally, the load transfer characteristics of the main roof are such that it unloads first, then arches, and after that unloads, until the original state of stress in the rock is restored. However, when the rate of advance is decelerated due to special reasons, secondary unloading will occur. For this reason, some scholars have proposed a time transfer factor KT [21-25], as given by the following:

$$
K_{t}=\frac{P_{z}}{K_{r} h_{1} l \rho g},
$$

where $P_{Z}$ is the load acting on the key block; $K_{r}$ is the lithology factor; $h_{1}$ is the thickness of the loading layer; $L$ is the length of the key block; and $\rho$ represents the average bulk density of the key layer.

At the same time, the author thinks that the time factor $K_{t}$ will change with time in the transformation process of the key blocks of the main roof. Therefore, the following formula can be obtained:

$$
K_{t}=m t
$$

where $m$ is the time factor.

Based on the above results, a velocity transfer factor $K_{V}$ suitable for the main roof load in the Huangling mining area is proposed. The velocity transfer factor $K_{V}$ will change with the speed, and the following formula can be obtained:

$$
K_{v}=n v
$$

where $n$ is the velocity factor.

During the periodic weighting of the main roof, when the rate of advance is kept constant, the periodic weighting step length is quasiconstant; therefore, it is considered that the periodic weighting step is a constant $S_{Z}$, and the load 


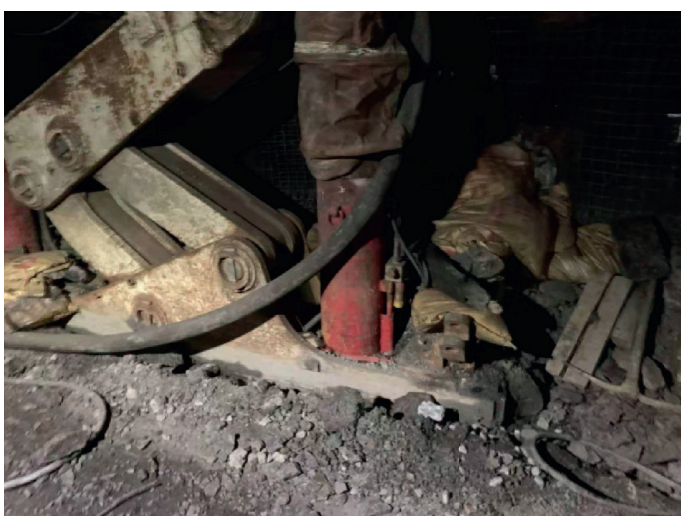

(a)

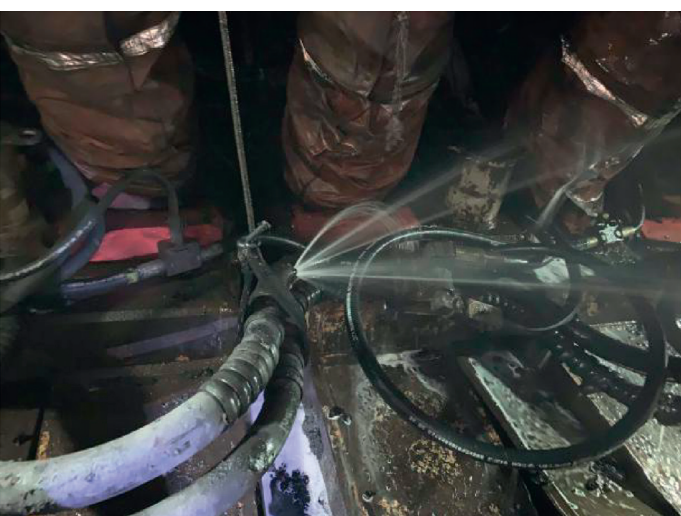

(b)

Figure 1: A failed support and hydraulic pipe explosion.

TABLE 1: Rock mechanics parameters.

\begin{tabular}{lcccccccc}
\hline $\begin{array}{l}\text { Serial } \\
\text { number }\end{array}$ & $\begin{array}{c}\text { Rock } \\
\text { properties }\end{array}$ & $\begin{array}{c}\text { Thickness } \\
(\mathrm{m})\end{array}$ & $\begin{array}{c}\text { Shear modulus } \\
(\mathrm{GPa})\end{array}$ & $\begin{array}{c}\text { Bulk modulus } \\
(\mathrm{GPa})\end{array}$ & $\begin{array}{c}\text { Density } \\
\left(\mathrm{g} / \mathrm{cm}^{3}\right)\end{array}$ & $\begin{array}{c}\text { Cohesion } \\
(\mathrm{MPa})\end{array}$ & $\begin{array}{c}\text { Internal friction } \\
\text { angle }\left(^{\circ}\right)\end{array}$ & $\begin{array}{c}\text { Tensile strength } \\
(\mathrm{MPa})\end{array}$ \\
\hline 1 & $\begin{array}{c}\text { Medium } \\
\text { sandstone }\end{array}$ & 28 & 6.23 & 5.07 & 2450 & 6.25 & 39 & 1.20 \\
2 & $\begin{array}{c}\text { Siltstone } \\
\text { Fine }\end{array}$ & 11.8 & 7.13 & 5.13 & 2350 & 4.24 & 37 & 1.12 \\
3 & sandstone & 8.7 & 5.78 & 4.70 & 2320 & 4.05 & 35 & 32 \\
4 & Coal & 2.1 & 2.81 & 1.68 & 1347 & 0.64 & 34 & 0.32 \\
5 & Mudstone & 2.8 & 4.87 & 3.06 & 2100 & 1.32 & 34 & 0.66 \\
\hline
\end{tabular}

TABLE 2: Comparison of rate of advance of working face in different periods

\begin{tabular}{lccc}
\hline Advance time (2019) & Advance duration $(\mathrm{d})$ & Advance speed $(\mathrm{m} / \mathrm{d})$ & Advance distance $(\mathrm{m})$ \\
\hline $6.1 \sim 6.18$ & 18 & 4.8 & 86.4 \\
$7.23 \sim 7.29$ & 7 & 12.8 & 89.6 \\
\hline
\end{tabular}

speed transfer factor $K_{v}$ at this time is deduced, as shown in the following formula:

$$
K_{v}=\frac{m n S_{z} K_{r} h_{1} l \rho g}{P_{z}}
$$

When the rate of advance changes, the periodic weighting step distance of the main roof also changes. The greater the rate of advance, the larger the periodic weighting step distance; therefore, the correction coefficient $m$ is introduced. According to the measured results of periodic weighting step distance of working face in the Huangling mining area, the value of correction coefficient $m$ is set (it is positively correlated with the rate of advance of the working face). Taking the advance speed of the 620 working face as an example, $m=1.2$, therefore, the load transfer speed factor $K_{v 1}$ applicable to the 620 working face is shown in the following formula:

$$
K_{v 1}=\frac{m n 1.2 \cdot S_{z} K_{r} h_{1} l \rho g}{P_{z}}
$$

Taking the load of the key block of the main roof, the extreme value of the speed factor $K_{v 0}$ for load transmission can be deduced as follows:

$$
K_{v 0}=1.2 S_{z} K_{r} m n .
$$

It can be seen from formula (6) that $K_{v 0}$ is jointly affected by periodic weighting step $S_{Z}$ and lithologic factor $K_{r}$ as determined by the thickness of load layer, lateral pressure coefficient, and internal friction angle, that is, given $K_{r}, m$, and $n$ being constant, it can be considered that $K_{v 0}$ is positively correlated with periodic weighting step $S_{Z}$. At the same time, periodic weighting step $S_{Z}$ is positively correlated with the rate of advance of the working face and load transfer factor $K_{v 0}$ is positively correlated with the rate of advance.

3.2. Reasonable Suspended Roof Length for Roof Pressure Relief. After the first fracture of the roof, with the continuous advance of the working face, one end of the roof rock beam is fixed on solid coal, and the other is suspended, showing a cantilever beam structure, and with the continuous advance of the working face, the roof periodically collapses [1, 26, 27]. If the roof load is evenly distributed, roof pressure will accumulate when stoppage occurs. Based on previous research results [28-30], the design relies on the drilling of several caving holes in the direct roof of the 


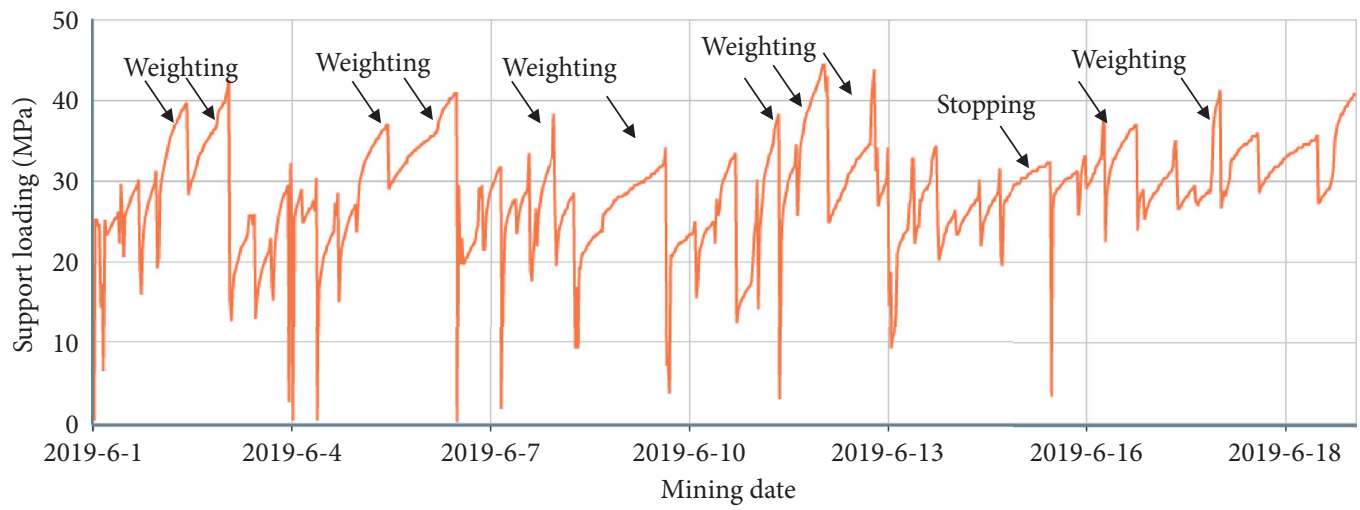

(a)

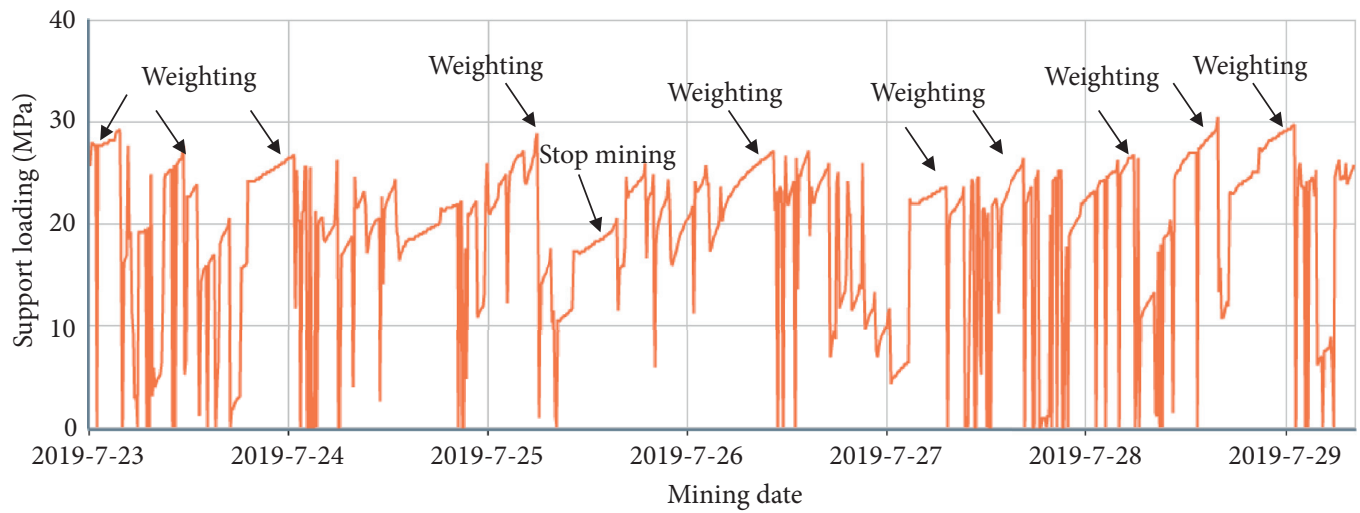

(b)

Figure 2: Load distribution on the support at different rates of advance. (a) Load distribution on the working face support when the rate of advance is $4.8 \mathrm{~m} / \mathrm{d}$. (b) Load distribution on the working face support when the rate of advance is $12.8 \mathrm{~m} / \mathrm{d}$.

TABLE 3: Measured pressure characteristics.

\begin{tabular}{lccccc}
\hline Advance speed $(\mathrm{m} / \mathrm{d})$ & $\begin{array}{c}\text { Times of periodic } \\
\text { weighting (frequency) }\end{array}$ & $\begin{array}{c}\text { Average periodic } \\
\text { weighting step }(\mathrm{m})\end{array}$ & Stoppage time $(\mathrm{h})$ & Load rise $(\mathrm{MPa})$ & Load rise rate $(\mathrm{MPa} / \mathrm{h})$ \\
\hline 4.8 & 11 & 7.2 & 6 & 5.7 & 0.95 \\
12.8 & 9 & 8.96 & 3 & 8.4 & 2.8 \\
\hline
\end{tabular}

gateway to release the roof pressure and assist the roof caving. Two sections are made along the gateway and the working face, and the mechanical model of roof pressure relief fracture is drawn, as shown in Figure 3 [31-33].

It can be seen from Figure 3 that the load layer above the main roof exerts a uniform load $Q$ on the main roof. If there are $I$ caving holes under construction and the load released by each caving hole is $Q$, the support resistance provided by the support to the working face is the allowable support resistance $[P]$. According to the fact that the support can bear all the loads within the roof control area, then

$$
\begin{aligned}
\frac{1}{2}[P] a^{2} & =\frac{1}{2}(Q-i q) L^{2}, \\
{[P] } & =\frac{(Q-i q)(a+b)^{2}}{a^{2}},
\end{aligned}
$$

where $a$ is the distance of support control, $L$ is the distance of hanging roof, and $L=a+b$.
Forced caving is used to ensure that the working resistance $P$ provided by the support is not greater than the allowable support resistance $[P]$ in case of periodic roof fracture. Then,

$$
\begin{aligned}
P \leq[P] & =\frac{(Q-i q)(a+b)^{2}}{a^{2}}, \\
b & \geq a\left(\sqrt{\frac{[P]}{Q-i p}}-1\right) .
\end{aligned}
$$

The reasonable length of the suspended roof based on the pressure relief of the caving hole and the allowable support resistance $[P]$ of the support can be calculated:

$$
L \leq a \sqrt{\frac{[P]}{Q-i p}} .
$$

According to formula (9), after the working face is determined, the roof control distance of the support and the 


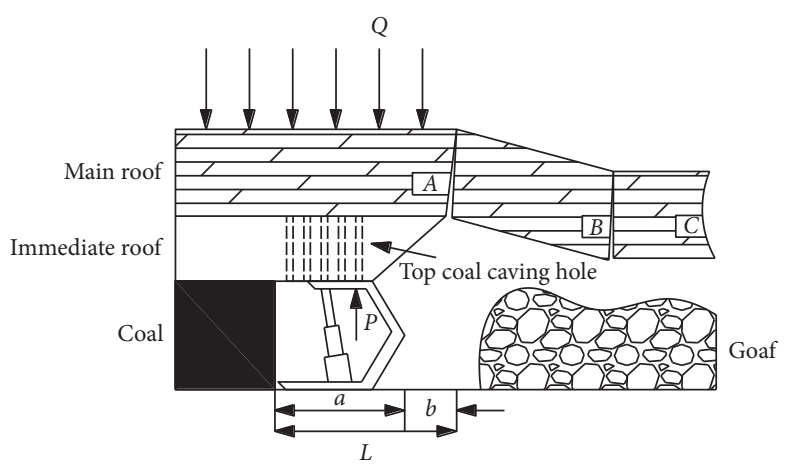

(a)

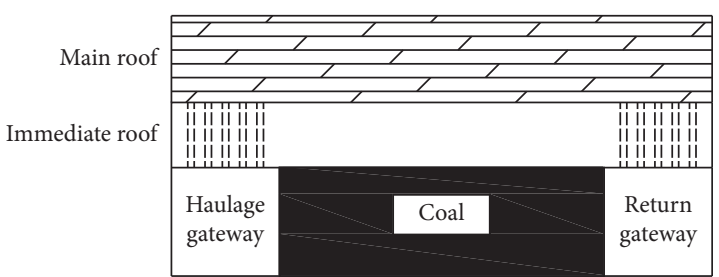

(b)

Figure 3: Mechanical model of roof pressure relief.

allowable support resistance of the support are determined, and the main roof load is also determined. Therefore, the reasonable hanging roof length is mainly affected by the number of caving holes and the pressure relief effect.

\section{Numerical Simulation Study}

4.1. Establishment of Model. FLAC ${ }^{3 \mathrm{D}}$ finite difference simulation software is used here: the Mohr-Coulomb constitutive relationship is set for rock stratum and a strain-softening constitutive relationship is applied to model the coal seam. The mechanical parameters of rock mass are provided by the mine. To simplify the stratum, the strike direction is $345 \mathrm{~m}$, the advancing direction length is $300 \mathrm{~m}$, the vertical thickness is $81 \mathrm{~m}$, and the thickness of the coal seam is $3 \mathrm{~m}$. A total of 354,960 elements and 371,124 nodes are established. We limit the displacement around the model, fix the bottom, apply a $5 \mathrm{MPa}$ uniform load to the top of the model, and assume a lateral pressure coefficient of 1.2. The numerical simulation model is shown in Figure 4. The numerical simulation mainly analyses the distribution of advance abutment pressure after the working face reaches a stable rate of advance. After the working face is advanced by $100 \mathrm{~m}$, three measuring lines are established to monitor the abutment pressure distribution characteristics within $50 \mathrm{~m}$ ahead of the working face. The three monitoring lines are located on both sides of goaf and the middle of goaf, respectively. When simulating the advancing process of working face, the unit mining depth of the working face is replaced by time steps, and the difference of rate of advance is characterised by the difference in total operation steps $[2,7,8]$. Among them, the same excavation step distance and different excavation steps are used to replace the propulsion speed. The specific advancing scheme is summarised in Table 4 .

\subsection{Analysis of Simulation Results}

(1) Analysis of advance abutment pressure distribution under different rates of advance:

Figure 5 shows the distribution diagram of abutment pressure on the advancing (by $100 \mathrm{~m}$ ) mining face under different rates of advance. Combined with the data in Figure 4, the characteristics of roof pressure at different rates of advance are plotted, using data in Table 5. The analysis shows that, with the continuous increase of the rate of advance, the bearing pressure first decreases and then decelerates. When the rate of advance of the working face reaches $15 \mathrm{~m} / \mathrm{d}$, the weakening trend of the advanced abutment pressure will diminish. Compared with the rate of advance of $20 \mathrm{~m} / \mathrm{d}$, the stress concentration in each case is similar. Compared with the slow rate of advance, the stress concentration is smaller when the rate of advance reaches $15 \mathrm{~m} / \mathrm{d}$; at the same time, it is concluded that, in a certain range of rate of advance, increasing the rate of advance reduces the working face pressure, but when the rate of advance reaches a certain value, the change in the rate of advance has little influence on the weighting of the working face.

(2) Analysis of advance abutment pressure distribution in different times of stopping mining under different rates of advance:

Taking survey line 1 as an example, the difference in abutment pressure at different stopping times under different rates of advance is analysed. Figure 6 shows the distribution of advanced abutment pressure at different stopping times at different rates of advance of line 1, and Table 6 shows the concentrated characteristics of stopping production pressure at different rates of advance of line 1. Accordingly, the peak position of advanced abutment pressure appears at about $12 \mathrm{~m}$ from the coal wall, and the abutment pressure first increases and then decreases with the distance of the leading coal wall; at the same time, the degree of concentration of abutment pressure also increases with the extension of the stoppage time. According to the data in Table 6, the range of pressure change is not large when the mining is stopped for 2 days or 3 days, so it is speculated that the roof pressure concentration had stabilised.

(3) Analysis of maximum eigenvalue variation of abutment pressure at different rates of advance: 


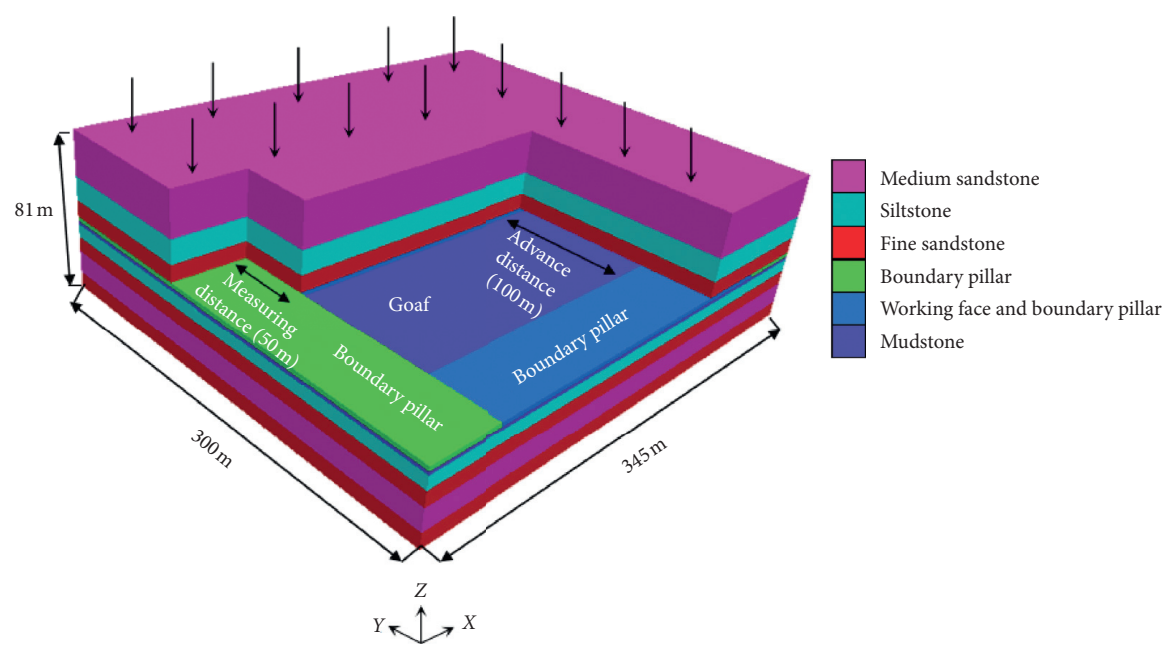

FIgURE 4: Numerical simulation model.

Table 4: Design of different face-advance schemes.

\begin{tabular}{|c|c|c|c|c|c|}
\hline Serial number & Programme & $\begin{array}{c}\text { Unit mining } \\
\text { depth }(\mathrm{m})\end{array}$ & $\begin{array}{c}\text { Advance } \\
\text { speed }(\mathrm{m} / \mathrm{d})\end{array}$ & Advance time steps of primary mining & Total steps \\
\hline 1 & Advancing $100 \mathrm{~m}$ & 5 & 5 & 2000 & 40000 \\
\hline 2 & Advancing $100 \mathrm{~m}$ and stopping for 1 day & 5 & 5 & 4000 & 42000 \\
\hline 3 & Advancing $100 \mathrm{~m}$ and stopping for 2 days & 5 & 5 & 6000 & 44000 \\
\hline 4 & Advancing $100 \mathrm{~m}$ and stopping for 3 days & 5 & 5 & 8000 & 46000 \\
\hline 5 & Advancing $100 \mathrm{~m}$ & 10 & 10 & 2000 & 20000 \\
\hline 6 & Advancing $100 \mathrm{~m}$ and stopping for 1 day & 10 & 10 & 4000 & 22000 \\
\hline 7 & Advancing $100 \mathrm{~m}$ and stopping for 2 days & 10 & 10 & 6000 & 24000 \\
\hline 8 & Advancing $100 \mathrm{~m}$ and stopping for 3 days & 10 & 10 & 8000 & 26000 \\
\hline 9 & Advancing $100 \mathrm{~m}$ & 15 & 15 & 2000 & 14000 \\
\hline 10 & Advancing $100 \mathrm{~m}$ and stopping for 1 day & 15 & 15 & 4000 & 16000 \\
\hline 11 & Advancing $100 \mathrm{~m}$ and stopping for 2 days & 15 & 15 & 6000 & 18000 \\
\hline 12 & Advancing $100 \mathrm{~m}$ and stopping for 3 days & 15 & 15 & 8000 & 20000 \\
\hline 13 & Advancing $100 \mathrm{~m}$ & 20 & 20 & 2000 & 10000 \\
\hline 14 & Advancing $100 \mathrm{~m}$ and stopping for 1 day & 20 & 20 & 4000 & 12000 \\
\hline 15 & Advancing $100 \mathrm{~m}$ and stopping for 2 days & 20 & 20 & 6000 & 14000 \\
\hline 16 & Advancing $100 \mathrm{~m}$ and stopping for 3 days & 20 & 20 & 8000 & 16000 \\
\hline
\end{tabular}

Figure 7 shows the variation in the maximum eigenvalue of different rates of advance. It can be seen from Figure 6 that the maximum eigenvalue gradually decreases with the increase of the rate of advance, and the increment of the stress peak value changes to a significant extent in the process of the gradual acceleration of the rate of advance. When the rate of advance reaches $15 \mathrm{~m} / \mathrm{d}$, the peak stress increase presents a downward trend. Compared with the four curves in Figure 7, it can be seen that, with the continuous increase of the rate of advance of the working face, the increase of the maximum eigenvalue is significant: the rate of change of abutment pressure increment at different stoppage times is also accelerated. When the working face stops mining for 1 day, the increment of abutment pressure changes most, then, with the increase of stoppage time, the increment of abutment pressure gradually decreases and finally diminishes; therefore, it can be concluded that the faster the rate of advance of working face, the greater the roof pressure caused by stopping mining. When the rate of advance reaches a certain value, the roof pressure will increase and the increment of abutment pressure then will decrease.

\section{Engineering Application}

Combining with the characteristics of support load distribution in the 620 working face with different rates of advance in the past, it is necessary to take some pressure relief measures according to the pressure accumulation phenomenon when stopping mining at different rates of advance in the 620 working face, so as to release the roof pressure and maintain the safety and stability of the working face. Taking the stoppage of 620 working face on 8 August 2019 as an example, the current daily rate of advance is $12.8 \mathrm{~m} / \mathrm{d}$, and the method of constructing a caving hole is adopted to release roof pressure locally to assist goaf caving. The MQT-120T pneumatic drill pipe machine is used for construction. The first row is $3 \mathrm{~m}$ from the coal wall of the 


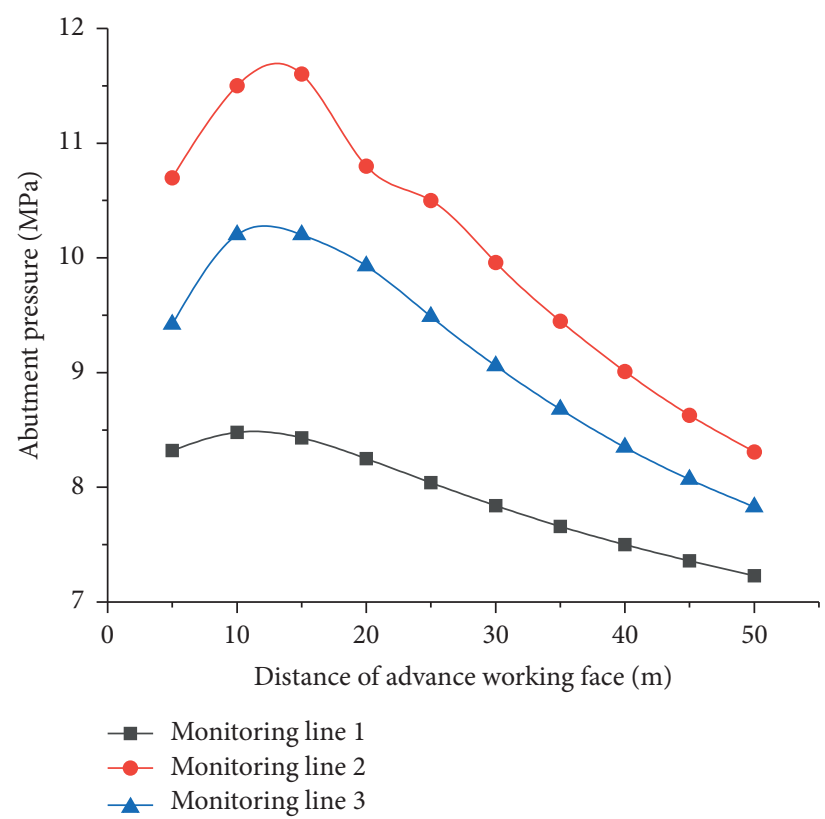

(a)

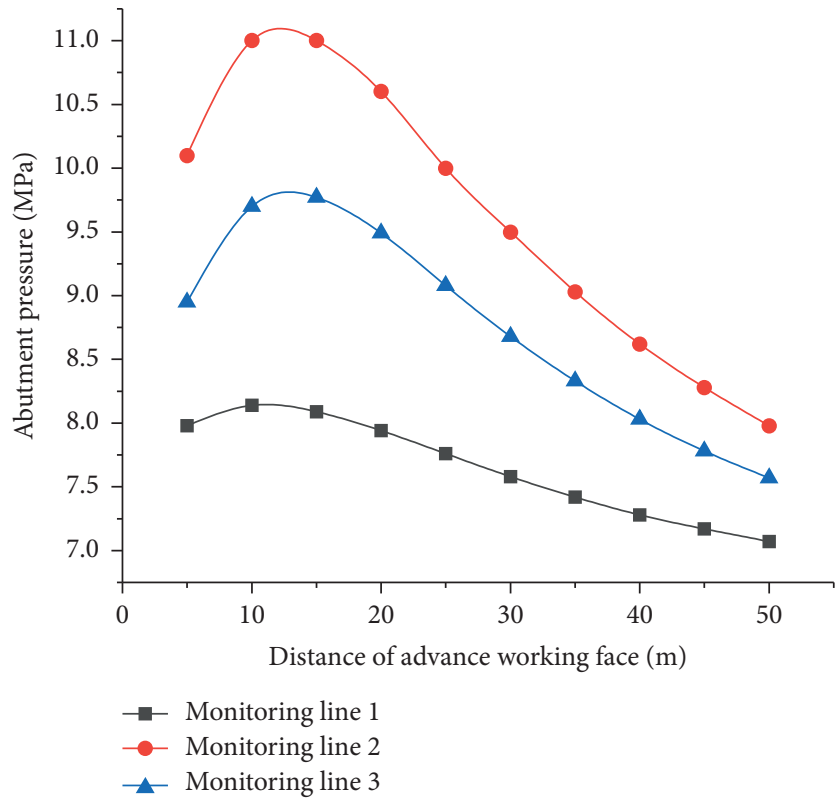

(c)

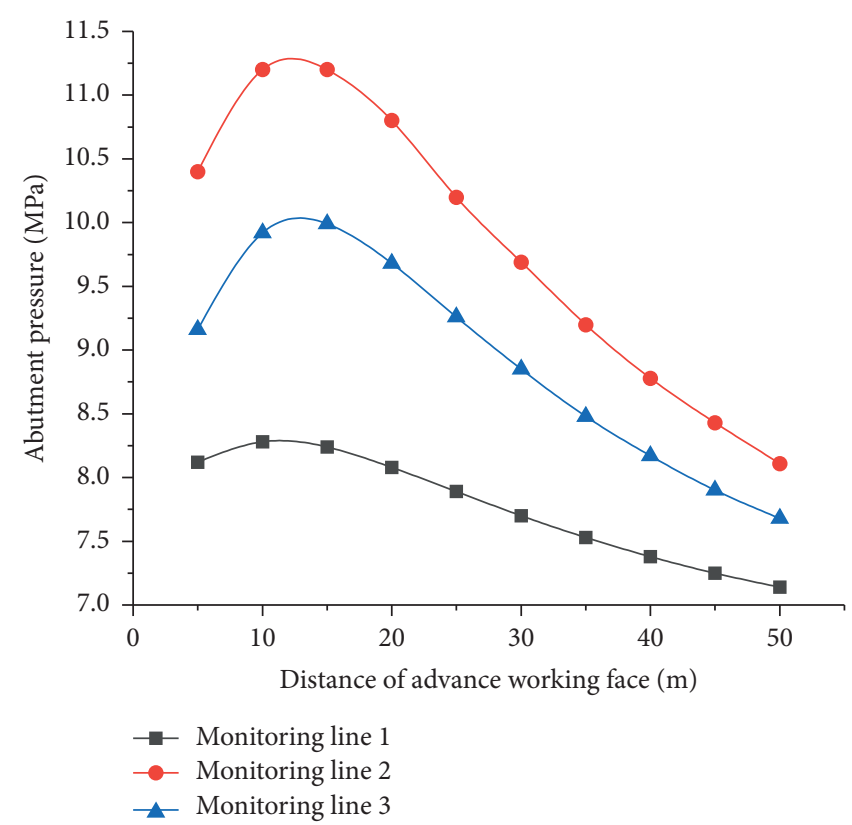

(b)

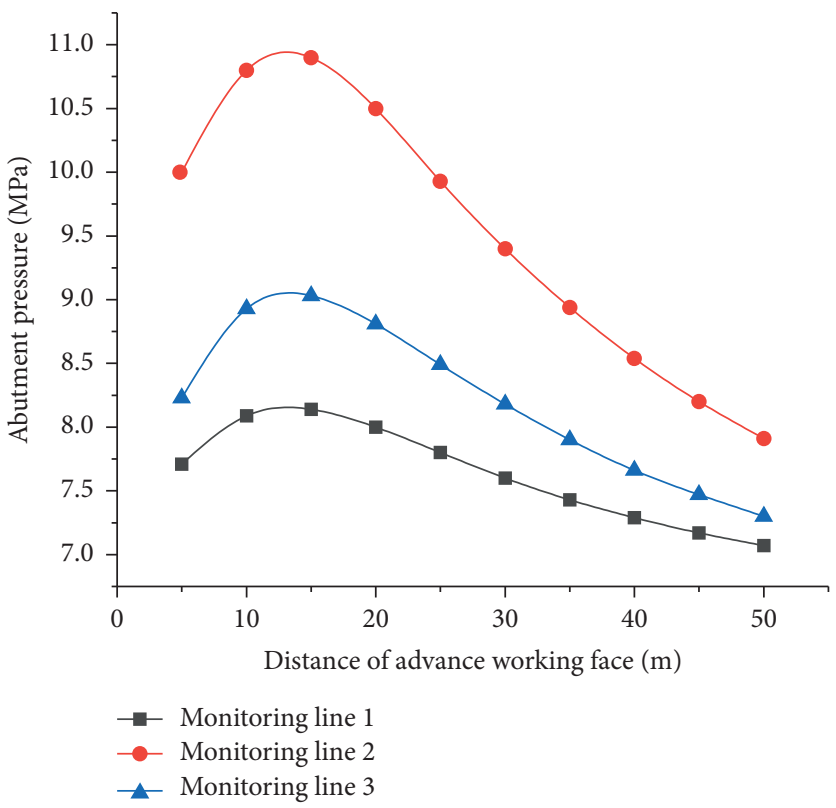

(d)

FIGURE 5: Distribution of advance bearing pressure of the working face under different rates of advance. Advance speed of (a) $5 \mathrm{~m} / \mathrm{d}$, (b) $10 \mathrm{~m} / \mathrm{d}$, (c) $15 \mathrm{~m} / \mathrm{d}$, and (d) $20 \mathrm{~m} / \mathrm{d}$.

TABLE 5: Roof pressure characteristics at different rates of advances.

\begin{tabular}{|c|c|c|c|c|c|c|}
\hline \multirow{2}{*}{ Advance speed $(\mathrm{m} / \mathrm{d})$} & \multicolumn{3}{|c|}{ Abutment pressure peak value $(\mathrm{MPa})$} & \multicolumn{3}{|c|}{ Peak stress concentration factor } \\
\hline & Survey line 1 & Survey line 2 & Survey line 3 & Survey line 1 & Survey line 2 & Survey line 3 \\
\hline 5 & 8.48 & 11.6 & 10.2 & 1.37 & 1.87 & 1.65 \\
\hline 10 & 8.28 & 11.2 & 9.99 & 1.34 & 1.81 & 1.61 \\
\hline 15 & 8.14 & 11.0 & 9.77 & 1.31 & 1.77 & 1.58 \\
\hline 20 & 8.14 & 10.9 & 9.03 & 1.31 & 1.76 & 1.45 \\
\hline
\end{tabular}




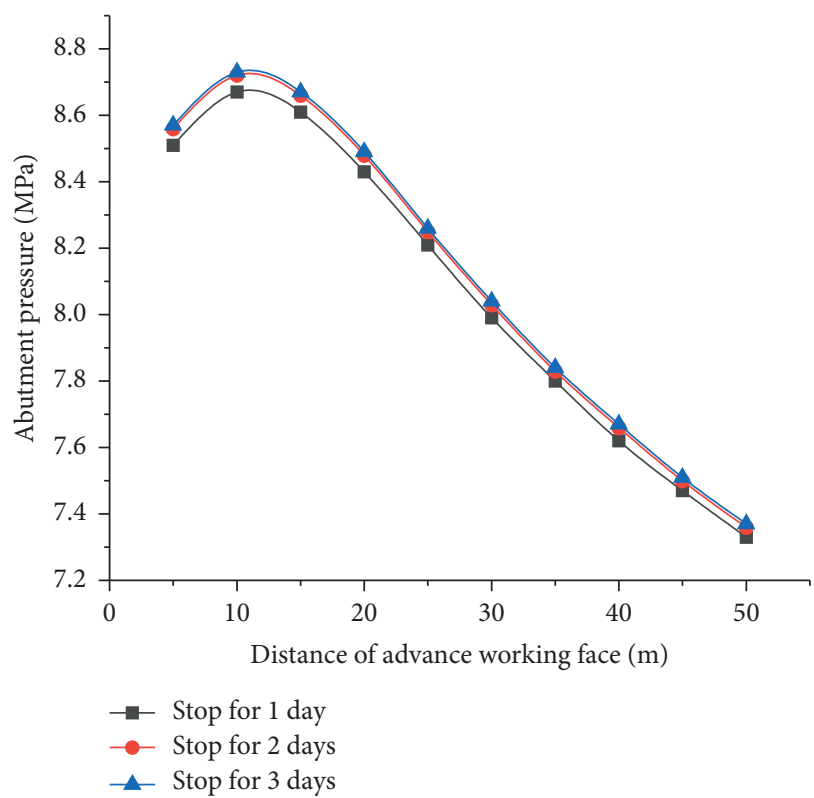

(a)

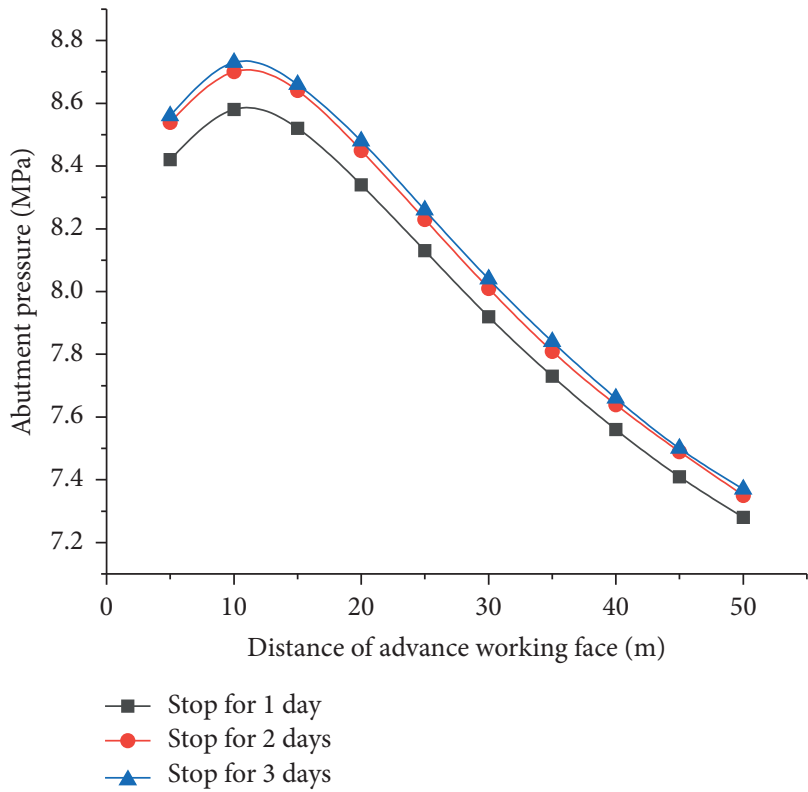

(c)

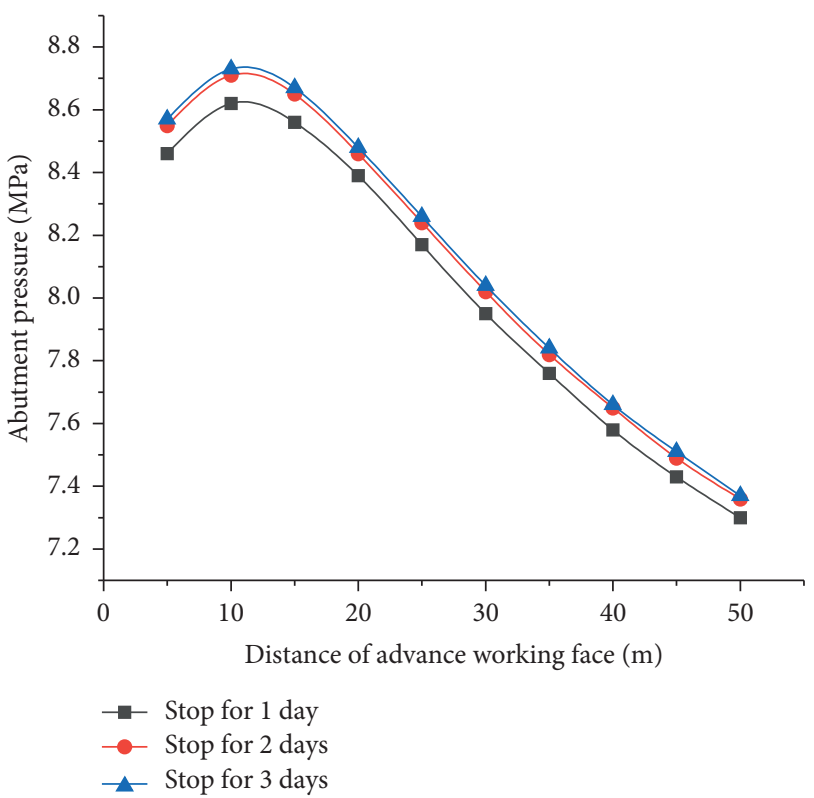

(b)

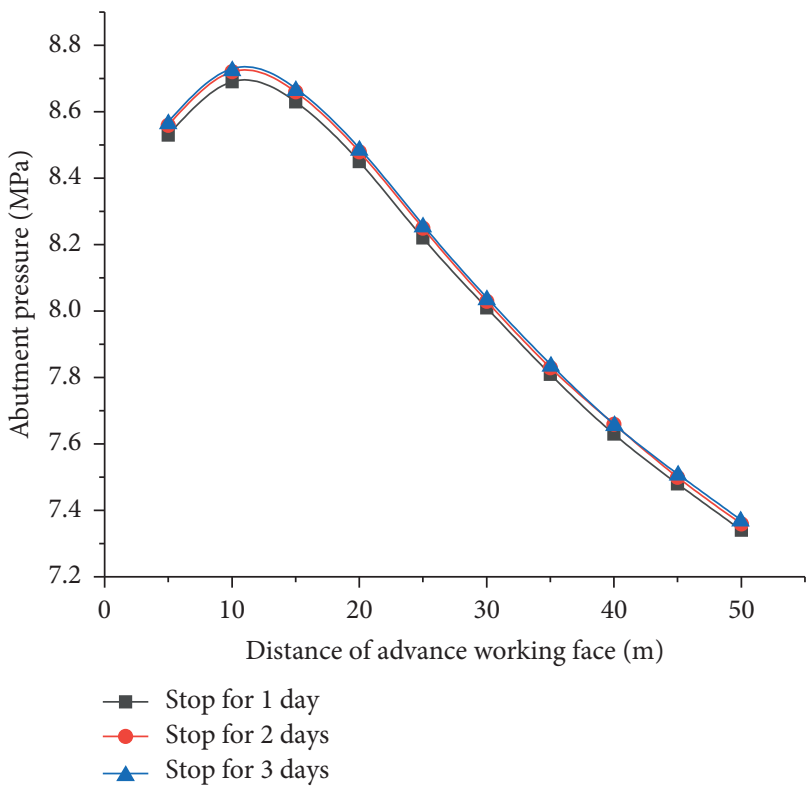

(d)

Figure 6: Distribution of advance support pressures at different stoppage times at different rates of advance. Advance speed of (a) $5 \mathrm{~m} / \mathrm{d}$, (b) $10 \mathrm{~m} / \mathrm{d}$, (c) $15 \mathrm{~m} / \mathrm{d}$, and (d) $20 \mathrm{~m} / \mathrm{d}$.

goaf, with 13-15 rows in each row. The spacing between rows is $300 \times 4000 \mathrm{~mm}$, the hole depth is $8 \mathrm{~m}$, and the hole diameter is $28 \mathrm{~mm}$. At the same time, a discharge top hole is constructed at a spacing of $300 \mathrm{~mm}$ from the side slope of the solid coal (Figure 8).

As shown in Figure 9, the two instances of the sudden drop of support load to zero are due to the decline of working face support and the separation of support top beam and roof, resulting in no load above the support. Periodic weighting occurs at the working face at about 06 : 00 , and the peak load on the support is $36.2 \mathrm{MPa}$. The roof then collapses and the support load decreases. The time from peak weighting to stoppage is about $6 \mathrm{~h}$. During this period of time, at about $11: 00$, the top beam of the support dropped and separated from the roof, resulting in a sudden drop of the support load to zero, and at 15:07, the working face suffers from tile failure. At this time, the support load increases slowly, the peak load is $23.8 \mathrm{MPa}$, the load increase is 6.3 $\mathrm{MPa}$, and the duration of pressurisation is $1.8 \mathrm{~h}$. At the same time, forced caving measures are taken to release the roof pressure. At this time, the support load drops sharply, the final load decreases to $11.7 \mathrm{MPa}$, and the cumulative load decreases by $12.1 \mathrm{MPa}$. Compared with the support load before and after pressure relief, the load rise rate caused by 
TABLE 6: Concentration characteristics of stoppage pressure at different rates of advance: line 1.

\begin{tabular}{|c|c|c|c|c|c|c|c|c|c|}
\hline \multirow[b]{2}{*}{$\begin{array}{l}\text { Advance } \\
\text { speed }(\mathrm{m} / \mathrm{d})\end{array}$} & \multicolumn{3}{|c|}{ Abutment pressure peak value (MPa) } & \multicolumn{3}{|c|}{$\begin{array}{l}\text { Amount of abutment pressure increase } \\
(\mathrm{MPa})\end{array}$} & \multicolumn{3}{|c|}{ Rate of increase (\%) } \\
\hline & $\begin{array}{l}\text { Stop } \\
\text { mining for } \\
1 \text { day }\end{array}$ & $\begin{array}{l}\text { Stop mining } \\
\text { for } 2 \text { days }\end{array}$ & $\begin{array}{l}\text { Stop mining } \\
\text { for } 3 \text { days }\end{array}$ & $\begin{array}{c}\text { Stop } \\
\text { mining for } \\
1 \text { day }\end{array}$ & $\begin{array}{l}\text { Stop mining } \\
\text { for } 2 \text { days }\end{array}$ & $\begin{array}{l}\text { Stop mining } \\
\text { for } 3 \text { days }\end{array}$ & $\begin{array}{c}\text { Stop } \\
\text { mining for } \\
1 \text { day }\end{array}$ & $\begin{array}{l}\text { Stop mining } \\
\text { for } 2 \text { days }\end{array}$ & $\begin{array}{l}\text { Stop mining } \\
\text { for } 3 \text { days }\end{array}$ \\
\hline 5 & 8.67 & 8.72 & 8.73 & 0.19 & 0.24 & 0.25 & 2.24 & 2.83 & 2.95 \\
\hline 10 & 8.62 & 8.71 & 8.73 & 0.34 & 0.43 & 0.45 & 4.11 & 5.19 & 5.43 \\
\hline 15 & 8.58 & 8.70 & 8.73 & 0.44 & 0.56 & 0.59 & 5.41 & 6.87 & 7.25 \\
\hline 20 & 8.69 & 8.72 & 8.73 & 0.55 & 0.58 & 0.59 & 6.76 & 7.12 & 7.25 \\
\hline
\end{tabular}

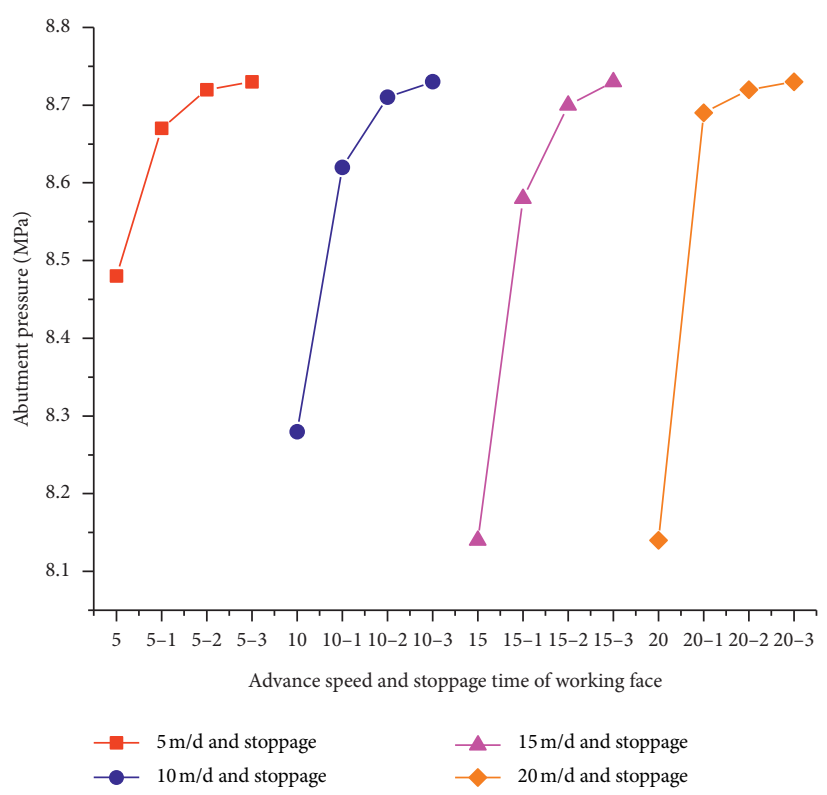

FIgURE 7: Maximum characteristic value changes for different rates of advance.

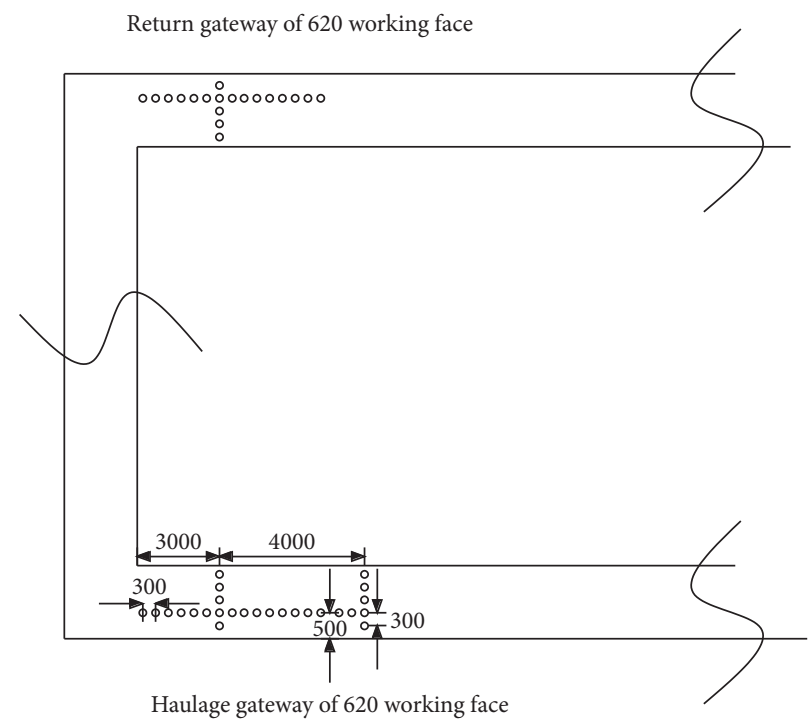

FIgURE 8: Caving hole layout parameters. 


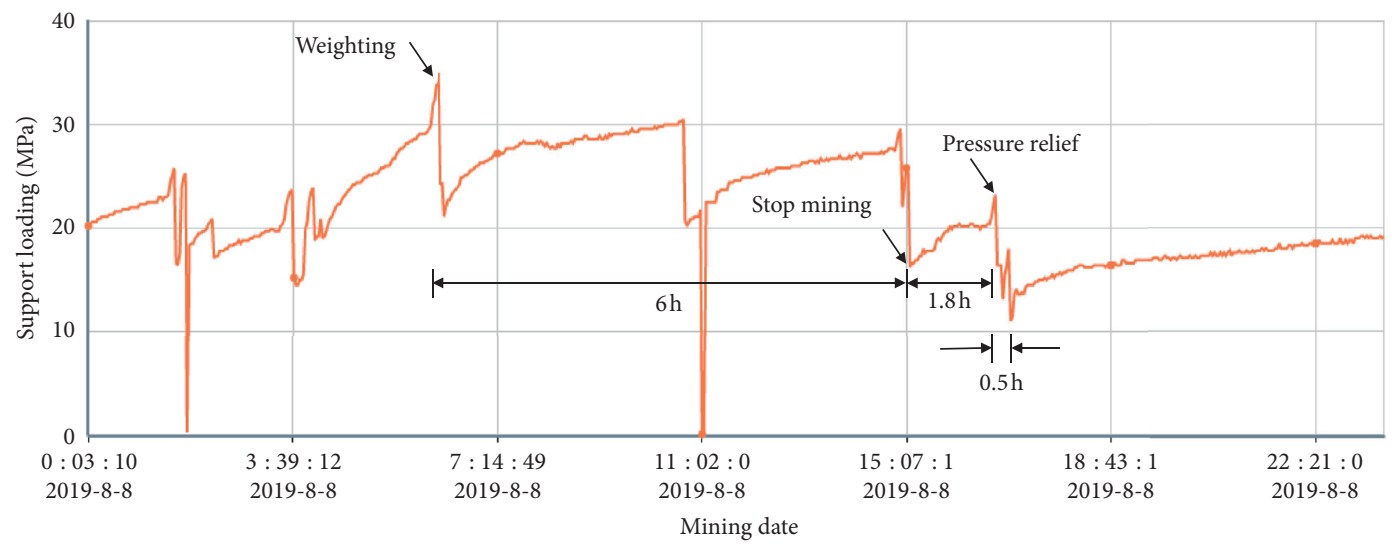

Figure 9: Load distribution on the support on 8 August 2019.

stopping mining is $3.5 \mathrm{MPa} / \mathrm{h}$, that caused by forced caving is $23.4 \mathrm{MPa} / \mathrm{h}$, the load drop rate is 6.68 times the previous rate of rise, and the forced caving pressure relief effect is obvious.

\section{Conclusion}

(1) The load transfer velocity factor $K_{v}$ of a working face is affected by lithology factor $K_{r}$ and the periodic weighting step. After the working face is calculated, $K_{v}$ is determined accordingly; that is, the load transfer speed factor applicable to the working face is positively correlated with the rate of advance of the working face.

(2) The reasonable hanging roof length based on the allowable support resistance of the support is mainly affected by the number of caving holes and the pressure relief effect.

(3) With the continuous increase of the rate of advance of working face, the advance abutment pressure first decreases and then tends to be stable. At different stoppage times, the incremental trend of roof abutment pressure varies: with the continuous extension of stoppage time, the increment of roof abutment pressure decreases, but when the rate of advance increases to within a certain range, the trend of abutment pressure increment decreases.

(4) The roof has accumulated part of energy after the working face has been excavated continuously after normal cycle weighting. If a stoppage then occurs, the roof pressure accumulation is significant, so it is necessary to take forced roof caving measures to control the roof pressure.

\section{Data Availability}

The data used to support the findings of this study are available from the corresponding author upon request.

\section{Conflicts of Interest}

The authors declare that they have no conflicts of interest.

\section{References}

[1] M. G. Qian, P. W. Shi, and J. L. Xu, Mine Pressure and Strata Control, China University of mining and Technology Press, Xu Zhou, China, 2010.

[2] G. X. Xie, J. C. Chang, and X. Z. Hua, "Influence of mining velocity on mechanical characteristics of surrounding rock in fully mechanized top-coal caving face," Chinese Journal of Geotechnical Engineering, vol. 29, no. 7, pp. 963-967, 2007.

[3] G. Xie, Z. Yin, L. Wang, Z. Hu, and C. Zhu, "Effects of gas pressure on the failure characteristics of coal," Rock Mechanics and Rock Engineering, vol. 50, no. 7, pp. 1711-1723, 2017.

[4] Q. Li, G. X. Xie, and P. Zou, "Energy source and energy dissipation mechanism of coal and gas outburst based on microscope," Acta Microscopica, vol. 29, no. 4, pp. 1900-1910, 2020.

[5] D. F. Yang, Study on Roof Cutting Mechanism of High Intensity Mining in Western Shallow Seam, China University of mining and Technology, Beijing, China, 2016.

[6] Q. M. Liu, "Analysis on the effect of advancing speed on the ground pressure appearance in shallow fully mechanized mining face," Coal Science and Technology, vol. 38, no. 7, pp. 24-26, 2010.

[7] S. L. Yang, Z. H. Wang, Z. H. Wang, and J. H. Yang, "Analysis on the effect of advancing speed of coal rock disaster in high strength mining face," Journal of Coal Science, vol. 41, no. 3, pp. 586-594, 2016.

[8] S. L. Yang, G. F. Song, and J. H. Yang, "An analytical solution for the geometric broken characteristics of the overlying strata and its physical modeling study in longwall coal mining," Arabian Journal Of Geosciences, vol. 13, no. 3, 2020.

[9] Z. B. Cheng, S. L. Yang, L. H. Li, and L. F. Zhang, "Support working resistance determined on top-coal caving face based on coal-rock combined body," Geomechanics \& Engineering, vol. 19, no. 3, pp. 155-168, 2020.

[10] S. L. Yang, G. F. Song, and D. Z. Kong, "An evaluation of longwall face stability in thick coal seams through a basic understanding of shield-strata interaction," Journal of Geophysics and Engineering, vol. 16, no. 1, pp. 125-135, 2019.

[11] D. Z. Kong, Y. Liu and S. S. Zheng, "Sensitivity analysis of influencing factors and control technology for coalface failure," Arabian Journal Of Geosciences, vol. 12, no. 17, 2019.

[12] G. F. Song, K. Ding, and D. Z. Kong, "Assessing longwall shield-strata interaction using a physical model," The Quarterly Journal of Engineering Geology and Hydrogeology, vol. 52, no. 4, 2019. 
[13] J. H. Yang, S. L. Sun and D. Z. Kong, "The effect of face length and advance speed on the occurrence of pressure in high strength mining face," Rock and Soil Mechanics, vol. 36, no. S2, pp. 333-339, 2015.

[14] Z. J. Zhu, H. W. Zhang, and Y. Chen, Y. P. Li and W. D. Wu, "The influence of the advancing speed of the working face on the mine pressure appearance in the extra thick coal seam," Journal of Safety and Environment, vol. 16, no. 3, pp. 126-129, 2016.

[15] Y. F. Xu, S. K. An, C. Xu, Y. C. Chen, and H. Yi, "Influence of advancing speed on strata beh-aviors in fully-mechanized face with hard roof," Journal of Safety Science and Tech-nology, vol. 15, no. 10, pp. 88-94, 2019.

[16] L. F. Feng, L. M. Dou, X. D. Wang, D. W. Ji, and W. Cai, "Mechanism of mining speed on energy release from hard roof movement," Journal of Coal Science, vol. 44, no. 11, pp. 3329-3339, 2019.

[17] C. Y. Wang, "Effect of mining speed on bump manifestation of fully-mechanized mining face in deep and thick coal seam," Coal Science and Technology, vol. 47, no. 8, pp. 96-101, 2019.

[18] F. F. Zheng, Z. G. Sun, and S. G. Li, "Yield mining theory and roof control technology at end mining stage of fully mechanized face," Mining safety \& Environmental protection, vol. 42, no. 2, pp. 64-67, 2015

[19] X. Z. Wang, J. L. Xu, W. B. Zhu, and J. F. Ju, "Influence of high mining velovity on periodice weighting during fully-mechanized mining in a shallow seam," Journal of China University of Science \& Technology, vol. 41, no. 3, pp. 349-354, 2012.

[20] X. Z. Wang, J. F. Ju, and J. L. Xu, "Theory and applicable of yield mining at ending stage of fully-mechanized face in shallow seam at shendong mine area," Journal of Mining \& Safety Engineering, vol. 29, no. 2, pp. 151-156, 2012.

[21] Q. X. Huang, "Studies on load-transmitting factor of thick sandy soil layer on key roof stratum in shallow seam mining," Chinese Journal of Geotechnical Engineering, vol. 27, no. 6, pp. 672-676, 2005.

[22] Q. X. Huang, J. L. Zhou, and J. Cao, "Key stratum structure and support working resistance of longwall face with large mining height in the shallow coal seams, China," Advances in Civil Engineering, vol. 2020, Article ID 8834403, 14 pages, 2020.

[23] Q. X. Huang and J. Cao, "Research on coal pillar malposition distance based on coupling control of three-field in shallow buried closely spaced multi-seam mining," Energies, vol. 12, no. 3, 2019.

[24] Q. X. Huang, Y. P. He, and F. Li, "Research on the roof advanced breaking position and influences of large mining height working face in shallow coal seam," Energies, vol. 13, no. 7, 2020.

[25] P. Zhang, Study on Roof Dynamic Structure of Shallow Seam Longwall Mining, Xi'an University of science and technology, Xian, China, 2012.

[26] J. F. Ju, J. L. Xu, and Q. X. Wang, "Cantilever structure moving type of key strata and its influence on ground pressure in large mining height workface," Journal of Coal Science, vol. 36, no. 12, pp. 2115-2120, 2011.

[27] S. H. Yan, X. W. Yin, G. J. Hu, G. Xu, and L. Yu, "Roof structure of short cantilever-articulated rock beam and calculation of support resistance in full-mechanized face with large mining height," Journal of Coal Science, vol. 36, no. 11, pp. 1816-1820, 2011

[28] Z. H. Chen, J. J. Feng, C. C. Xiao, and R. H. Li, "Fracture mechanical model of key roof for fully-mechanized top-coal caving in shallow thick coalseam," Journal of Coal Science, vol. 5, pp. 449-452, 2007.

[29] K. Wang, T. H. Kang, H. T. Li, and W. M. Han, "Study of control caving methods and reasonable hanging roof length on hard roof," Chinese Journal of Rock Mechanics and Engineering, vol. 28, no. 11, pp. 2320-2327, 2009.

[30] J. Li, H. Duan, D. Yue, P. J. Chen and Z. H. Li, "Study on the fracture mechanics model of forced caving of hard roof," Coal Geology \& Exploration, vol. 46, no. 6, pp. 128-132, 2018.

[31] D. Z. Kong, Z. B. Cheng, and S. S. Zheng, "Study on the failure mechanism and stability control measures in a large-cuttingheight coal mining face with a deep-buried seam," Bulletin of Engineering Geology and the Environment, vol. 78, no. 8, pp. 6143-6157, 2019.

[32] Z. B. Cheng, L. H. Li, and Y. N. Zhang, "Laboratory investigation of the mechanical properties of coal-rock combined body," Bulletin of Engineering Geology and the Environment, vol. 79, no. 4, pp. 1947-1958, 2020.

[33] J. F. Lou, F. Q. Gao, and J. H. Yang, "Characteristics of evolution of mining-induced stress field in the longwall panel: insights from physical modeling," International Journal of Coal Science \& Technology, 2021. 